\title{
Routine screening for psychosocial distress following hematopoietic stem cell transplantation
}

\author{
SJ Lee ${ }^{1}$, FR Loberiza ${ }^{2}$, JH Antin ${ }^{1}$, T Kirkpatrick ${ }^{1}$, L Prokop ${ }^{1}$, EP Alyea ${ }^{1}$, C Cutler $^{1}$, VT Ho ${ }^{1}$, \\ PG Richardson ${ }^{1}$, RL Schlossman ${ }^{1}$, DC Fisher ${ }^{1}$, B Logan $^{2}$ and RJ Soiffer ${ }^{1}$ \\ ${ }^{1}$ Department of Adult Oncology, Dana-Farber Cancer Institute, Boston, MA, USA; and ${ }^{2}$ Health Policy Institute, Medical College of \\ Wisconsin, Milwaukee, WI, USA
}

\section{Summary:}

The diagnosis and treatment of cancer is often associated with high levels of psychosocial distress, yet exploration of these issues is rarely included in routine oncologic care. We conducted a pilot study to evaluate the feasibility of screening for psychosocial distress after autologous and allogeneic stem cell transplantation. A total of 80 adults were enrolled in Boston, MA, USA. Subjects completed selfadministered assessments prior to hospital admission, at their first clinic visit after hospital discharge, and at 100 days post transplant. Assessments included validated instruments assessing psychosocial distress and quality of life (QOL). Elevated levels of anxiety and/or depression were detected in $55 \%$ of those providing pre-transplant assessments and were associated with compromised QOL. Post transplant screening was successfully performed in $69 \%$ of subjects and identified that $44 \%$ had symptoms of depression, anxiety or post traumatic stress disorder. Pretransplant distress was associated with detection of distress after transplantation (81 vs $13 \%, P<0.0001)$. In summary, we detected high levels of distress in transplant patients using self-administered tools. Pre-transplant distress appears to be highly predictive of distress post transplant and is a feasible marker to target screening and intervention programs.

Bone Marrow Transplantation (2005) 35, 77-83.

doi:10.1038/sj.bmt.1704709

Published online 25 October 2004

Keywords: screening; depression; anxiety; quality of life; stem cell transplantation

Even among previously functional people, the diagnosis and treatment of cancer is often associated with high levels of psychosocial distress. ${ }^{1-6}$ Yet, fewer than $10 \%$ of oncology patients receive psychosocial therapy. ${ }^{7}$ The National Comprehensive Cancer Network (NCCN) has produced guidelines for recognizing, evaluating and treat-

Correspondence: Dr SJ Lee, Dana-Farber Cancer Institute, Boston, MA 02115, USA; E-mail: stephanie_lee@dfci.harvard.edu

Received 25 May 2004; accepted 3 August 2004

Published online 25 October 2004 ing psychosocial distress, which they broadly define as 'an unpleasant experience of an emotional, psychological, social or spiritual nature that interferes with the ability to cope with cancer treatment. It extends along a continuum, from common normal feelings of vulnerability, sadness, and fears, to problems that are disabling, such as true depression, anxiety, panic, and feeling isolated or in a spiritual crisis. ${ }^{7}$

Traditionally, most psychosocial monitoring and care is provided by social workers, nurses, psychologists, psychiatrists and clergy. However, this support is often delivered separately from routine clinical care. Studies document multiple physician, patient and practical barriers to detecting psychosocial distress and delivering appropriate interventions. ${ }^{5,8-16}$ Oncologists' reviews of systems rarely include psychosocial problems. ${ }^{12,17}$ Reasons include time constraints, competing medical issues, lack of training in the recognition and management of psychosocial distress, fear of unleashing strong patient emotions, discomfort with or disinterest in psychosocial issues, and uncertainty about the value of psychosocial interventions. Patients may not report psychosocial distress to their physicians fearing stigma, being a burden on busy clinical staff, or distracting the physician from curative efforts. They may feel that to acknowledge psychosocial problems is a sign of weakness, or that distress is inevitable and cannot be helped. Finally, practical barriers can hinder appropriate treatment even after distress is recognized. These include lack of easily accessible psychosocial providers and difficulty in obtaining insurance coverage for services.

At our center, psychosocial care following HSCT is heavily reliant on clinical detection of distress during medical visits. Psychosocial resources such as nurses, social workers, and psychiatrists are available, but are involved on an as-needed basis as perceived by the psychosocial practitioners and transplant physicians. We conducted this pilot study to see if we could effectively screen for psychosocial distress following HSCT by evaluating people at distinct timepoints with self-administered assessments.

Subjects and methods

\section{Subjects}

Potential subjects were recruited for participation from English-speaking adult patients undergoing HSCT at the 
Dana-Farber Cancer Institute/Brigham and Women's Hospital, Boston, MA, USA. The Institutional Review Board approved the protocol, and all participants provided signed, informed consent. People who already carried a psychiatric diagnosis and/or were on psychotropic medications were eligible to participate. Patients were excluded if they were unable to complete self-administered batteries due to language, cognitive or psychological difficulties. Subjects were asked to complete self-assessments prior to transplantation, at their first clinic visit after hospital discharge (marking the first time they were healthy enough to leave the hospital), and at 100 days post-HSCT (a clinically meaningful milestone and an appropriate interval from the last screening). Patients identified as seriously distressed on post transplant assessments were contacted by the Principal Investigator to discuss their assessment results and offered referrals for additional evaluation. No actions were taken based on results of pre-transplant assessments, as patients were about to undergo prolonged hospitalizations.

\section{Instruments}

Copies of the psychosocial batteries are available from the corresponding author. The pre-transplant assessment was used to measure baseline levels of anxiety and depression. It contained the Spielberger State Anxiety Scale, ${ }^{18}$ the Beck Depression Inventory (BDI), ${ }^{19,20}$ the Medical Outcomes Study social support scale, ${ }^{21}$ the Brief COPE, ${ }^{22}$ and sociodemographics. In total, 35 of the 38 subjects $(92 \%)$ completing the baseline assessment reported feeling very comfortable or comfortable with the questions. Three subjects did not answer the question. The pre-transplant battery contained 163 items and the median time required for completion was $30 \mathrm{~min}$ (range 15-90 min). Nine subjects did not report completion time.

The post transplant screening instruments were identical for the first clinic visit and 100 days. They included validated modules for depression, anxiety, and post traumatic stress disorder as well as general measures for social, psychological, practical and spiritual distress. The screening instruments were intended to identify patients who required further professional evaluation and were not considered definitive for any psychiatric diagnoses. The post transplant screening batteries included the BDI, Hospital Anxiety and Depression Scale (HADS), ${ }^{23-26}$ Patient Health Questionnaire (PHQ), ${ }^{27,28}$ post traumatic stress disorder (PTSD) module, ${ }^{29-32}$ NCCN Distress Thermometer, ${ }^{7}$ and functional and quality of life measures (SF-36, FACT-BMT subscale). ${ }^{33-36}$ Morisky's medication compliance scale was used to assess medication compliance through self-report at the post transplant assessments only. ${ }^{37}$ In anticipation of a randomized clinical trial, we purposely included several instruments different from the ones used for pre-HSCT assessment. The post transplant assessments contained 74 items; we did not ask subjects how long it took to complete them. Almost all respondents (82/84 assessments, $98 \%$ ) felt very comfortable or comfortable when answering questions on the post transplant batteries. Two subjects reported feeling a little uncomfortable. Clinical data were abstracted from medical charts or retrieved from the transplant program database.

\section{Outcomes and statistical analysis}

Instruments were scored according to published conventions. 'Distressed' individuals were defined as those whose scores showed 'moderate/intermediate' or worse anxiety, depression and/or post traumatic stress symptoms. Specifically, we considered an individual distressed if they scored $\geqslant 40$ on the Spielberger State Anxiety scale, $\geqslant 8$ on the anxiety or depression components of the HADS, $\geqslant 16$ on the BDI, or $\geqslant 10$ on the PHQ, or had a PTSD total score $\geqslant 50$ or scores of 3 or more on $\geqslant 1$ intrusion item, $\geqslant 3$ avoidance/numbing items and $\geqslant 2$ arousal symptoms. ${ }^{18-20,23-32}$ Subjects scoring in the normal or 'mild' range were considered 'nondistressed.' Comparisons between distressed and nondistressed populations were carried out using $\chi^{2}$ or Fisher's exact tests for categorical variables and Wilcoxon rank-sum tests for continuous variables. Spearman correlations were calculated between different depression screening instruments using only the first post transplant assessment completed by each subject. 'Successful' post transplant screening was defined as completion of the screening instrument at either the first clinic visit after hospital discharge or 100 days post transplant.

The NCCN Distress thermometer was scored for each topic with $\geqslant 5$ indicating psychosocial difficulties. ${ }^{7}$

\section{Results}

\section{Participants}

In total, 83 people signed the informed consent document between August 2002 and February 2003 and were registered to the protocol. Three were never transplanted, and $61 / 80(76 \%)$ provided at least one assessment and were considered evaluable although three subjects died within the first 100 post transplant days (days 60, 81, 92). The median age was 49 years, and 56\% underwent allogeneic procedures with $44 \%$ receiving autologous grafts. No adverse events due to study participation were noted.

During the enrollment period, 135 people were transplanted at our institution. Table 1 shows the characteristics of study participants as well as the 19 people (14\%) who signed a consent form and were enrolled, but did not return any self-assessments, and the 55 people not participating in the study $(41 \%)$. The three groups were similar with the following exceptions: People who signed consent forms were more likely to be White (98 vs $87 \%, P=0.02$ ) than those who never signed consent forms. The reasons for not signing consent were not tracked but likely include: exclusion because of language barrier or physician preference, never being offered participation because of logistical oversight, and patient refusal. Of the people who signed consent, people who did not return any assessments (nonevaluable, $n=19$ ) were more likely to die within the first 100 days than those who returned at least one self-assessment (evaluable, $n=61$ ) (26 vs $5 \%$, $P=0.02)$

Of the 61 subjects enrolled who completed at least one assessment, $38(62 \%)$ returned pre-transplant batteries, 46 $(75 \%)$ returned their first clinic visit assessments and $41 / 58$ 
Table 1

Population characteristics

\begin{tabular}{|c|c|c|c|c|}
\hline Variables & $\begin{array}{c}\text { Signed consent and } \\
\text { participated }\end{array}$ & $\begin{array}{c}\text { Signed consent, did not } \\
\text { participate }\end{array}$ & $\begin{array}{l}\text { Never signed } \\
\text { consent }\end{array}$ & $P$-value \\
\hline$N$ & 61 & 19 & 55 & \\
\hline Median age in years (range) & $49(20-72)$ & $49(26-69)$ & $47(20-70)$ & NS \\
\hline Male sex $(\%)$ & $31(51 \%)$ & $10(53 \%)$ & $35(64 \%)$ & NS \\
\hline White race $(\%)$ & $60(98 \%)$ & $18(95 \%)$ & $48(87 \%)$ & $P 1=0.02$ \\
\hline Disease stage at transplant (\%) & & & & NS \\
\hline Good & $6(10 \%)$ & $2(11 \%)$ & $5(9 \%)$ & \\
\hline Intermediate & $44(72 \%)$ & $13(68 \%)$ & $35(64 \%)$ & \\
\hline Poor & $11(18 \%)$ & $4(21 \%)$ & $15(27 \%)$ & \\
\hline Type of transplant (\%) & & & & NS \\
\hline Autologous & $27(44 \%)$ & $10(53 \%)$ & $16(29 \%)$ & \\
\hline Allogeneic, nonmyeloablative & $17(28 \%)$ & $2(11 \%)$ & $18(33 \%)$ & \\
\hline Allogeneic, myeloablative & $17(28 \%)$ & $7(37 \%)$ & $21(38 \%)$ & \\
\hline Stem cell source & & & & NS \\
\hline Bone marrow & $6(10 \%)$ & $2(11 \%)$ & $4(7 \%)$ & \\
\hline Peripheral blood & $54(88 \%)$ & $17(89 \%)$ & $51(93 \%)$ & \\
\hline Bone marrow and peripheral blood & $1(2 \%)$ & $0(0 \%)$ & $0(0 \%)$ & \\
\hline T-cell depletion $(\%)$ & $2(3 \%)$ & $2(11 \%)$ & $3(5 \%)$ & NS \\
\hline Deaths within first 100 days & $3(5 \%)$ & $5(26 \%)$ & $9(16 \%)$ & $P 2=0.02$ \\
\hline Median follow-up of survivors, months (range) & $6(3-12)$ & NA & NA & \\
\hline
\end{tabular}

$P 1=P$-value comparing those who signed consent and those who did not sign consent.

$P 2=P$-value comparing those who signed consent and participated to those who signed consent and did not participate.

$\mathrm{NS}=P 1$ and $P 2$ not significant; NA $=$ not applicable.

100-day survivors (71\%) returned their 100-day assessments. Considering return of at least one post transplant assessment to be successful screening, 55/80 (69\%) of consented subjects were screened.

\section{Distress prior to transplantation}

Of the 38 pre-transplant assessments returned, $17(45 \%)$ scored within the normal or mild range for both anxiety and depression, while $21(55 \%)$ were in the distressed range for either or both. Autologous and allogeneic patients were equally likely to be distressed ( 53 vs $57 \%, P=0.85$ ). Table 2 shows that subjects distressed before transplantation reported significantly worse functioning in the areas of social functioning, vitality, role emotional, mental health, overall mental functioning, BMT-specific symptoms, and emotional and overall social support. Distressed subjects were more likely to have taken a prescription drug for anxiety or depression, have seen a psychologist or psychiatrist, and have seen a social worker in the prior 6 months than nondistressed people. However, there was no difference in self-reported performance status or global assessment of overall health between the distressed and nondistressed subjects.

\section{Distress after transplantation}

Of the 55 subjects who had evaluable post transplant screenings, $31(56 \%)$ never met distressed criteria for anxiety, depression, or PTSD (Table 3). The other 24 $(44 \%)$ subjects screened positive at either the first clinic visit or 100-day assessment with 'moderately' or greater anxiety, depression, or PTSD signaling 'distress'. Auto- logous and allogeneic patients were equally likely to be distressed after HSCT (36 vs 50\%, $P=0.30$ ). Patients who did and did not complete pre-transplant assessments were equally likely to report post transplant distress (47 vs 39\%, $P=0.56)$.

The correlation between the BDI and HADS-depression subscale was $r=0.70, P<0.0001$, while the correlation between the BDI and PHQ was $r=0.66, P<0.0001$ (55 observations). In total, 10 people $(18 \%)$ answered 'yes' to the question, 'Are you depressed?' All 10 screened positive for depression with one of the other instruments. Psychosocial difficulties detected with the NCCN distress thermometers were greatest for emotional issues $(25 \%)$, followed by practical issues such as housing, insurance, work $(22 \%)$, and family issues (18\%). Spiritual/religious difficulties were uncommon $(2 \%)$. Less than $10 \%$ indicated on their assessments that they wanted someone from nursing, social work, psychiatry or clergy to call them.

Distress detected post transplant was associated with self-reported medication nonadherence (58 vs 32\%, $P=0.05$ ) (Table 4). Distressed people were also more likely to take prescription medications for anxiety (71 vs $26 \%$, $P=0.0009$ ), depression (46 vs 19\%, $P=0.04$ ) and sleep (83 vs 55\%, $P=0.03$ ) than nondistressed people. Rates of support group participation were low in both groups as expected given that patients are usually isolated from large crowds early post transplant.

\section{Correlation between pre- and post transplant distress}

Table 5 summarizes the results of all 80 subjects who signed informed consents according to whether pre- and post 
Table 2 Differences between distressed and not distressed subjects as measured at baseline $(N=38)$

\begin{tabular}{|c|c|c|c|c|c|}
\hline Baseline & $N$ & Not distressed ${ }^{\mathrm{a}}(N=17,45 \%)$ & $N$ & Distressed $(N=21,55 \%)$ & $P$-value \\
\hline Self-reported health status & & $N(\%)$ & & $N(\%)$ & \\
\hline KPS $\geqslant 80$ & 15 & $12(80 \%)$ & 19 & $14(74 \%)$ & 1.0 \\
\hline 'Excellent' or 'very good' health & 15 & $10(67 \%)$ & 20 & $9(45 \%)$ & 0.31 \\
\hline SF36 & & Median $(I Q R)$ & & Median $(I Q R)$ & \\
\hline Physical composite scale & 17 & $47(37-51)$ & 19 & $39(28-49)$ & 0.19 \\
\hline Mental composite scale & 17 & $57(53-60)$ & 19 & $42(34-52)$ & $<0.0001$ \\
\hline Physical functioning & 17 & $90(60-95)$ & 21 & $70(45-80)$ & 0.10 \\
\hline Social functioning & 17 & $100(75-100)$ & 21 & $50(38-75)$ & 0.002 \\
\hline Vitality & 17 & $70(55-85)$ & 21 & $35(25-60)$ & 0.0004 \\
\hline Role physical & 17 & $75(0-100)$ & 20 & $25(0-75)$ & 0.14 \\
\hline Role emotional & 17 & $100(100-100)$ & 21 & $33(0-100)$ & 0.002 \\
\hline Mental health & 17 & $88(80-92)$ & 21 & $60(48-72)$ & $<0.0001$ \\
\hline Pain & 17 & $84(74-100)$ & 21 & $74(41-100)$ & 0.06 \\
\hline General health & 17 & $67(50-80)$ & 20 & $60(36-71)$ & 0.20 \\
\hline FACT-BMT subscale & 17 & $31(29-35)$ & 21 & $24(19-26)$ & $<0.0001$ \\
\hline \multicolumn{6}{|l|}{ MOS Social support } \\
\hline Overall & 17 & $99(96-100)$ & 21 & $74(66-87)$ & 0.0006 \\
\hline Affective & 17 & $100(100-100)$ & 21 & $100(75-100)$ & 0.17 \\
\hline Emotional & 17 & $97(97-100)$ & 21 & $66(50-81)$ & 0.0001 \\
\hline Social & 17 & $100(100-100)$ & 21 & $92(67-100)$ & 0.01 \\
\hline Tangible & 17 & $100(100-100)$ & 21 & $88(63-100)$ & 0.01 \\
\hline Experience with psychosocial supports before transplantation & & $N(\%)$ & & $N(\%)$ & \\
\hline Took a prescription drug for anxiety or depression & 17 & $5(29 \%)$ & 21 & $15(71 \%)$ & 0.01 \\
\hline Seen a psychologist or psychiatrist & 17 & $1(6 \%)$ & 21 & $7(33 \%)$ & 0.05 \\
\hline Seen a social worker & 17 & $4(24 \%)$ & 21 & $15(71 \%)$ & 0.008 \\
\hline \multicolumn{6}{|l|}{ Follow-up (of those providing baseline assessments) } \\
\hline Successfully screened & & $16(94 \%)$ & & $16(76 \%)$ & 0.20 \\
\hline Distressed in follow-up & & $2(13 \%)$ & & $13(81 \%)$ & $<0.0001$ \\
\hline
\end{tabular}

${ }^{\text {a}}$ Within the normal range for depression (BDI) and anxiety (STAI).

Table 3 Incidence of self-reported distress in the first 100 days post transplant $(N=55)$

\begin{tabular}{|c|c|c|c|c|c|}
\hline Categories & $\begin{array}{l}\text { Beck Depression } \\
\text { Inventory }\end{array}$ & $\begin{array}{l}\text { Hospital Anxiety and } \\
\text { Depression Scale } \\
\text { (Depression subscale) }\end{array}$ & $\begin{array}{l}\text { Hospital Anxiety and } \\
\text { Depression Scale } \\
\text { (Anxiety subscale) }\end{array}$ & $\begin{array}{l}\text { Patient Health } \\
\text { Questionnaire }\end{array}$ & $\begin{array}{l}\text { Post traumatic } \\
\text { stress disorder } \\
\text { (civilian version) }\end{array}$ \\
\hline Normal & $27(49 \%)$ & $45(82 \%)$ & $37(67 \%)$ & $21(38 \%)$ & $49(89 \%)$ \\
\hline Mild & $14(25 \%)$ & NA & NA & $19(35 \%)$ & NA \\
\hline Moderate/intermediate & $8(15 \%)$ & $2(4 \%)$ & $12(22 \%)$ & $7(13 \%)$ & NA \\
\hline Moderate-severe & NA & NA & NA & $4(7 \%)$ & NA \\
\hline Severe/definite & $6(11 \%)$ & $8(14 \%)$ & $6(11 \%)$ & $4(7 \%)$ & $6(11 \%)$ \\
\hline
\end{tabular}

$\mathrm{NA}=$ not applicable.

transplant assessments were completed and distress was detected or not. Of the 21 people scored as distressed pretransplant, 13 out of 16 who were screened post transplant $(81 \%)$ were still distressed. In contrast, of the 17 people scored as nondistressed pre-transplant, only two out of 16 who were screened post transplant $(13 \%)$ had become distressed. This suggests that people who were distressed before HSCT are more likely to screen positive for distress post transplant (81 vs $13 \%, P<0.0001)$. Although we do not know the baseline distress levels of the $23(38 \%)$ of subjects who did not complete pre-transplant assessments, $39 \%$ of this group screened positive for distress following transplantation. Analyzing the 32 subjects who provided a pre-transplant assessment and at least one post transplant assessment (represented by italics in Table 5), we calculated that pre-transplant distress predicts post transplant distress using our instruments with a sensitivity of $87 \%$, specificity of $82 \%$, positive predictive value of $81 \%$ and negative predictive value of $88 \%$.

\section{Correlation with medical records review}

Chart review revealed that subjects identified as distressed on at least one post transplant assessment were approxi- 
Table 4

Differences between distressed and not distressed subjects among subjects screened at the first clinic visit or 100 days post transplant $(N=55)$

\begin{tabular}{|c|c|c|c|}
\hline & Not distressed $N(\%)^{\mathrm{a}}$ & Distressed $N(\%)$ & $P$-value \\
\hline$N$ & $31(56 \%)$ & $24(44 \%)$ & \\
\hline Reports noncompliance with transplant medications & $10(32 \%)$ & $14(58 \%)$ & 0.05 \\
\hline Took a prescription drug for anxiety & $8(26 \%)$ & $17(71 \%)$ & 0.0009 \\
\hline Took a prescription drug for depression & $6(19 \%)$ & $11(46 \%)$ & 0.04 \\
\hline Took a prescription drug for sleep & $17(55 \%)$ & $20(83 \%)$ & 0.03 \\
\hline Participated in a support group & $2(6 \%)$ & $3(13 \%)$ & 0.64 \\
\hline Seen a psychologist & $2(6 \%)$ & $4(17 \%)$ & 0.39 \\
\hline Seen a psychiatrist & $4(13 \%)$ & $7(29 \%)$ & 0.18 \\
\hline Seen a social worker & $6(19 \%)$ & $10(42 \%)$ & 0.07 \\
\hline Seen a spiritual counselor & $7(23 \%)$ & $7(29 \%)$ & 0.58 \\
\hline
\end{tabular}

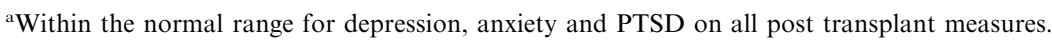

Table 5 Summary of pre- and post transplantation assessments from all enrolled subjects $(N=80)$

\begin{tabular}{lccc}
\hline $\begin{array}{l}\text { Results of pre-transplant } \\
\text { assessment }\end{array}$ & \multicolumn{2}{c}{ Results of post transplant screening } \\
\cline { 2 - 4 } & $\begin{array}{c}\text { Normal } \\
(N=31)\end{array}$ & $\begin{array}{c}\text { Distressed } \\
(N=24)\end{array}$ & $\begin{array}{c}\text { Not completed } \\
(N=25)\end{array}$ \\
\hline Normal $(N=17)$ & $14^{\mathrm{a}}$ & 2 & 1 \\
Distressed $(N=21)$ & 3 & 13 & 5 \\
Not completed $(N=42)$ & 14 & 9 & 19 \\
\hline
\end{tabular}

${ }^{a}$ Italic numbers represent the 32 subjects who were screened both before and after transplant. For example, 14 subjects scored as normal on both pre- and post transplant assessments.

mately twice as likely as subjects always screening within the normal range to be noted as distressed in the medical record (50 vs 23\%) through a combination of physician notation, social work notation, or follow-up mental health appointments. However, fully half of people screening positive for distress in our study did not have any notation of distress in their charts.

\section{Discussion}

We conclude from this pilot study that screening patients undergoing transplantation with self-administered instruments is feasible and important in the context of HSCT. Using our protocol, we detected a relatively high prevalence of psychosocial distress pre- and post transplant. This distress was in the form of depression, anxiety or PTSD, and was associated with self-reported medication nonadherence and use of prescription medications for anxiety, depression and sleep. All of the instruments tested appear to detect cases that may need psychosocial intervention. Further studies are warranted to see if formally integrating psychosocial screening into routine post transplant monitoring systems improves the success of HSCT. We plan to conduct such studies and selected different instruments for baseline and screening anticipating a randomized trial of screening $v s$ standard care in which we'd want endpoint and monitoring instruments to differ.
Prior studies of HSCT patients have shown an association between depression and decreased survival, controlling for physical status and clinical variables. ${ }^{38}$ In cardiology and renal transplantation studies, poor medication adherence has also been associated with increased morbidity and mortality, ${ }^{39-41}$ and depressed patients are more likely to be noncompliant. ${ }^{42} \mathrm{We}$ found a statistically significant association between self-reported distress and medication noncompliance using validated instruments. While this is only selfreport, it provides empirical evidence for at least one pathway by which distress can lead to decreased survival. Future studies should evaluate medication compliance with more objective measures controlling for the number of medications prescribed and the medical indications.

We found that pre-transplant detection of distress predicted detection of post transplant distress. Viewed another way, the third of the population who complete pretransplant assessments showing them to be within the normal range of anxiety and depression have only a $13 \%$ chance of reporting distress via self-assessment instruments in the first 100 days after transplantation. In addition, enrollment in our study but failure to complete pretransplant assessments was associated with a $39 \%$ incidence of distress following transplantation. This suggests that trials of screening and intervention might be most beneficial if targeted based on pre-transplant assessments. This also suggests that much of distress may be ongoing prior to transplant, and that post-HSCT events such as GVHD, prolonged hospitalization, and infections may primarily exacerbate distress rather than initiate it.

The potential for intervention and improvement of distress after HSCT is unknown. We found that many distressed people were already receiving prescription medications for anxiety and depression, and visits with psychologists, psychiatrists and social workers both preand post transplant. Although data are mixed from observational and smaller randomized studies, large randomized studies in other medical populations, most notably cardiology, have failed to demonstrate any improvement in survival or clinical outcomes with psychosocial screening and intervention programs. ${ }^{27,43-54}$ However, HSCT patients, most of whom face a higher probability of death and disability than the other populations studied, may form a particularly at risk group 
amenable to intervention. Following HSCT, patients need to take several antibiotics, antivirals, and/or immunosuppressive medications correctly in order to prevent complications. Return clinic visits and re-hospitalizations are common emphasizing the need for vigilance and medical compliance. The frequent interaction with physicians and the nature of HSCT suggest that screening and interventions for psychosocial distress could be implemented in the clinic. We chose to perform our first post transplant screening at the first clinic visit after hospital discharge because this was the earliest possible time to intervene as an outpatient. However, this visit took place at varying intervals from graft infusion, and could have influenced our detection of distress. We also elected to study selfadministered instruments as they seemed most feasible to broadly implement outside of the clinical encounter.

There are a number of limitations to this pilot study. First, although we were able to enroll $59 \%$ of all people transplanted at our institution during the study period, $41 \%$ either were not offered the study or declined to participate. Among those who enrolled, we received at least one assessment back from $76 \%$. Thus, we were able to study $45 \%$ of the total population. If nonparticipants are more distressed than our subjects, yet less likely to participate in research studies, we may not be reaching the group most likely to benefit from psychosocial screening. We note, however, that our response rate may have been compromised by the fact that study procedures were clearly identified as a pilot research protocol. We believe compliance would have been improved if either we had the resources to re-contact people failing to return an assessment or if psychosocial screening was viewed as standard clinical care by patients and physicians. Second, this is a single institution study, and methods for monitoring patients for psychosocial distress certainly vary. A recent survey study of transplant centers suggests that $50 \%$ have some sort of psychosocial monitoring program in place (Loberiza, personal communication, December 2003).

In summary, we have shown the feasibility of screening for distress associated with HSCT and the high burden faced by people undergoing this treatment modality. Our results suggest that targeting individuals who are distressed prior to transplant, or who fail to complete pre-transplant assessments, may be the most fruitful. Since other studies have found a strong association between depression and mortality, we believe that work focusing on development and testing of psychosocial interventions is warranted and offers the chance to improve both survival and quality of life.

\section{Acknowledgements}

We wish to thank Christina Caron, BA for her help with study management and data collection. This work was presented in part at the American Society of Hematology Meeting, 2003.

\section{References}

1 Carroll BT, Kathol RG, Noyes Jr R et al. Screening for depression and anxiety in cancer patients using the Hospital
Anxiety and Depression Scale. Gen Hosp Psychiatry 1993; 15: $69-74$.

2 de Leeuw JR, de Graeff A, Ros WJ et al. Prediction of depressive symptomatology after treatment of head and neck cancer: the influence of pre-treatment physical and depressive symptoms, coping, and social support. Head Neck 2000; 22: 799-807.

3 Bodurka-Bevers D, Basen-Engquist K, Carmack CL et al. Depression, anxiety, and quality of life in patients with epithelial ovarian cancer. Gynecol Oncol 2000; 78 (Part 1): 302-308.

4 Hopwood P, Stephens RJ. Depression in patients with lung cancer: prevalence and risk factors derived from quality-of-life data. J Clin Oncol 2000; 18: 893-903.

5 Fallowfield L, Ratcliffe D, Jenkins V, Saul J. Psychiatric morbidity and its recognition by doctors in patients with cancer. Br J Cancer 2001; 84: 1011-1015.

6 Zabora J, BrintzenhofeSzoc K, Curbow B et al. The prevalence of psychological distress by cancer site. Psychooncology 2001; 10: $19-28$.

7 Holland JC. NCCN practice guidelines for the management of psychosocial distress. National Comprehensive Cancer Network. Oncology (Huntington) 1999; 13: 113-147.

8 Worden JW, Weisman AD. Do cancer patients really want counseling? Gen Hosp Psychiatry 1980; 2: 100-103.

9 Sollner W, Zingg-Schir M, Rumpold G et al. Need for supportive counselling - the professionals' vs the patients' perspective. A survey in a representative sample of 236 melanoma patients. Psychother Psychosom 1998; 67: 94-104.

10 Passik SD, Dugan W, McDonald MV et al. Oncologists' recognition of depression in their patients with cancer. J Clin Oncol 1998; 16: 1594-1600.

11 Berard RM, Boermeester F, Viljoen G. Depressive disorders in an out-patient oncology setting: prevalence, assessment, and management. Psychooncology 1998; 7: 112-120.

12 Spitzer RL, Kroenke K, Williams JB. Validation and utility of a self-report version of PRIME-MD: the PHQ primary care study. Primary Care Evaluation of Mental Disorders. Patient Health Questionnaire. JAMA 1999; 282: 1737-1744.

13 Maguire P. Improving communication with cancer patients. Eur J Cancer 1999; 35: 1415-1422.

14 Rost K, Nutting P, Smith J et al. The role of competing demands in the treatment provided primary care patients with major depression. Arch Fam Med 2000; 9: 150-154.

15 Sollner W, DeVries A, Steixner E et al. How successful are oncologists in identifying patient distress, perceived social support, and need for psychosocial counselling? $\mathrm{Br}$ J Cancer 2001; 84: 179-185.

16 Eakin EG, Strycker LA. Awareness and barriers to use of cancer support and information resources by HMO patients with breast, prostate, or colon cancer: patient and provider perspectives. Psychooncology 2001; 10: 103-113.

17 Ford S, Fallowfield L, Lewis S. Doctor-patient interactions in oncology. Soc Sci Med 1996; 42: 1511-1519.

18 Smith RC, Lay CD. State and trait anxiety: an annotated bibliography. Psychol Rep 1974; 34: 519-594.

19 Beck AT, Ward CH, Mendelson M et al. An inventory for measuring depression. Arch Gen Psychiatry 1961; 4: 553-571.

20 Beck AT, Steer RA. Beck depression inventory manual. Antonio, TX: The Psychological Corporation, Harcourt Brace Jovanovich, 1993.

21 Sherbourne CD, Stewart AL. The MOS social support survey. Soc Sci Med 1991; 32: 705-714.

22 Carver CS. You want to measure coping but your protocol's too long: consider the brief COPE. Int J Behav Med 1997; 4: 92-100. 
23 Zigmond AS, Snaith RP. The hospital anxiety and depression scale. Acta Psychiatr Scand 1983; 67: 361-370.

24 Herrmann C. International experiences with the Hospital Anxiety and Depression Scale - a review of validation data and clinical results. J Psychosom Res 1997; 42: 17-41.

25 Spinhoven P, Ormel J, Sloekers PP et al. A validation study of the Hospital Anxiety and Depression Scale (HADS) in different groups of Dutch subjects. Psychol Med 1997; 27: 363-370.

26 Hjermstad MJ, Loge JH, Evensen SA et al. The course of anxiety and depression during the first year after allogeneic or autologous stem cell transplantation. Bone Marrow Transplant 1999; 24: 1219-1228.

27 Dobscha SK, Gerrity MS, Ward MF. Effectiveness of an intervention to improve primary care provider recognition of depression. Eff Clin Pract 2001; 4: 163-171.

28 Whooley MA, Avins AL, Miranda J, Browner WS. Casefinding instruments for depression. Two questions are as good as many. J Gen Intern Med 1997; 12: 439-445.

29 Smith MY, Redd WH, Peyser C, Vogl D. Post-traumatic stress disorder in cancer: a review. Psychooncology 1999; 8: 521-537.

30 Smith MY, Redd W, DuHamel K et al. Validation of the PTSD Checklist-Civilian Version in survivors of bone marrow transplantation. J Trauma Stress 1999; 12: 485-499.

31 Andrykowski MA, Cordova MJ, McGrath PC et al. Stability and change in posttraumatic stress disorder symptoms following breast cancer treatment: a 1-year follow-up. Psychooncology 2000; 9: 69-78.

32 Widows MR, Jacobsen PB, Fields KK. Relation of psychological vulnerability factors to posttraumatic stress disorder symptomatology in bone marrow transplant recipients. Psychosom Med 2000; 62: 873-882.

33 Ware JE, Snow KK, Kosinski M, Gandek B. SF-36 Health Survey: A Manual and Interpretation Guide. Boston: The Health Institute, New England Medical Center, 1993.

34 Ware JE, Kosinski M, Keller SD. SF-36 Physical and Mental Health Summary Scales: A User's Manual. Boston: The Health Institute, New England Medical Center, 1994.

35 Cella D. Manual of the Functional Assessment of Chronic Illness Therapy (FACIT) Measurement System. Version 4, Center on Outcomes, Research and Education (CORE), Evanston Northwestern Healthcare and Northwestern University, Evanston, IL, 1997.

36 McQuellon RP, Russell GB, Rambo TD et al. Quality of life and psychological distress of bone marrow transplant recipients: the 'time trajectory' to recovery over the first year. Bone Marrow Transplant 1998; 21: 477-486.

37 Morisky DE, Green LW, Levine DM. Concurrent and predictive validity of a self-reported measure of medication adherence. Med Care 1986; 24: 67-74.

38 Loberiza FR, Rizzo JD, Bredeson CN et al. Association of depressive syndrome and early deaths after stem-cell transplantation for malignant diseases. J Clin Oncol 2002; 20: 2118-2126.

39 Horwitz RI, Viscoli CM, Berkman L et al. Treatment adherence and risk of death after a myocardial infarction. Lancet 1990; 336: 542-545.
40 McDermott MM, Schmitt B, Wallner E. Impact of medication nonadherence on coronary heart disease outcomes. A critical review. Arch Intern Med 1997; 157: 1921-1929.

41 Greenstein S, Siegal B. Compliance and noncompliance in patients with a functioning renal transplant: a multicenter study. Transplantation 1998; 66: 1718-1726.

42 DiMatteo MR, Lepper HS, Croghan TW. Depression is a risk factor for noncompliance with medical treatment: metaanalysis of the effects of anxiety and depression on patient adherence. Arch Intern Med 2000; 160: 2101-2107.

43 Spiegel D, Bloom JR, Kraemer HC, Gottheil E. Effect of psychosocial treatment on survival of patients with metastatic breast cancer. Lancet 1989; 2: 888-891.

44 Fawzy FI, Cousins N, Fawzy NW et al. A structured psychiatric intervention for cancer patients. I. Changes over time in methods of coping and affective disturbance. Arch Gen Psychiatry 1990; 47: 720-725.

45 Reifler DR, Kessler HS, Bernhard EJ et al. Impact of screening for mental health concerns on health service utilization and functional status in primary care patients. Arch Intern Med 1996; 156: 2593-2599.

46 Williams Jr JW, Mulrow CD, Kroenke K et al. Case-finding for depression in primary care: a randomized trial. Am J Med 1999; 106: 36-43

47 Rost K, Nutting P, Smith $\mathbf{J}$ et al. Improving depression outcomes in community primary care practice: a randomized trial of the quEST intervention. Quality Enhancement by Strategic Teaming. J Gen Intern Med 2001; 16: 143-149.

48 Kroenke K, Taylor-Vaisey A, Dietrich AJ, Oxman TE. Interventions to improve provider diagnosis and treatment of mental disorders in primary care. A critical review of the literature. Psychosomatics 2000; 41: 39-52.

49 Thompson C, Kinmonth AL, Stevens L et al. Effects of a clinical-practice guideline and practice-based education on detection and outcome of depression in primary care: Hampshire Depression Project randomised controlled trial. Lancet 2000; 355: 185-191.

50 McLachlan SA, Allenby A, Matthews $\mathrm{J}$ et al. Randomized trial of coordinated psychosocial interventions based on patient self-assessments versus standard care to improve the psychosocial functioning of patients with cancer. J Clin Oncol 2001; 19: $4117-4125$

51 Goodwin PJ, Leszcz M, Ennis $\mathrm{M}$ et al. The effect of group psychosocial support on survival in metastatic breast cancer. $N$ Engl J Med 2001; 345: 1719-1726.

52 Friedman M, Thoresen CE, Gill JJ et al. Alteration of type A behavior and its effect on cardiac recurrences in post myocardial infarction patients: summary results of the recurrent coronary prevention project. Am Heart J 1986; 112: $653-665$.

53 Jones DA, West RR. Psychological rehabilitation after myocardial infarction: multicentre randomised controlled trial. BMJ 1996; 313: 1517-1521.

54 Berkman LF, Blumenthal J, Burg M et al. Effects of treating depression and low perceived social support on clinical events after myocardial infarction: the Enhancing Recovery in Coronary Heart Disease Patients (ENRICHD) Randomized Trial (comment). JAMA 2003; 289: 3106-3116. 